\title{
The case of interim denture applying for thermoforming technique
}

\author{
Jun-Gu Yun, Young-Gyun Song* \\ Department of Prosthodontics, College of Dentistry, Dankook University, Cheonan, Republic of Korea
}

Patients who get tooth loss would also lost their esthetic, stability and functional aspect suddenly. They have to get provisional restoration immediately. This case reports a satisfied result that thermoforming technique is good for patients to get injury from unexpected tooth loss. (J Dent Rehabil Appl Sci 2016;32(2):135-40)

Key words: thermoforming; tooth loss; interim denture

\section{서론}

최근 보철 수복에서 과정을 단순화 시키고 환자의 내 원 횟수를 줄여 시간을 단축하고자 하는 노력들이 많이 일어나고 있다. ${ }^{1}$ 그러나 보철적 수복에는 필수 불가결하 게 치과 기공작업을 위한 시간과 예후 관찰 등의 시간이 필요하기 때문에 임시 보철물이 필요하다. ${ }^{2}$ 임시 보철물 이란 '심미, 안정 그리고 제한된 기간 동안 기능을 확보 하기 위해 디자인 된 보철물' 로서 정의된다. ${ }^{3}$ 특히, 외상 과 같은 예상치 못한 상황으로 인해 보철 수복이 필요한 경우, 환자는 심미, 안정, 기능을 모두 급속히 상실하게 되며, 대부분의 경우 임시 보철물을 통한 빠른 회복이 요구된다. ${ }^{4}$

다양한 치과 영역에서 열형성 기술(themoforming technique)이 이용되고 있다. 열형성 기술 이란 열가소 성 polymer film 또는 plate에 열을 가하여 연화한 후 삼 차원적으로 늘려서 원하는 형태로 형성하고 다시 단 단하게 만드는 것을 말한다. ${ }^{5}$ 본 증례에서 사용한 열

*Correspondence to: Young-Gyun Song

Assistant Professor, Department of Prosthodontics, College of Dentistry,

Dankook University, 119, Dandae-ro, Dongnam-gu, Cheonan, 31116, Republic of Korea

Tel: +82-41-550,1932, Fax: +82-41-550-0116, E-mail: ygsong@dankook.ac.kr Received: June 16, 2016/Last Revision: June 19, 2016/Accepted: June 20, 2016
형성 재료는 Erkocryl rose (Erkocryl rose $2.0 \mathrm{~mm}$, ERKODENT, Pfalzgrafenweiler, Germany)이며 이 를 열형성하여 임시 의치의 의치상으로 이용하였다. Erkocryl roes는 polymethylmethacrylate (PMMA) 계열 로 자가 중합 아크릴 레진과 화학적 결합이 가능하다. 따라서 제작 과정에서 레진치와의 화학적 결합을 도모 할 수 있다. 본 증례는 예상치 못하게 치아 상실이 일어 난 환자에게 신속하고 간편하게 임시 의치로 수복하여 만족할 만한 결과를 얻었다.

\section{증례 보고}

첫 번째 환자는 46세의 남자 환자로 외상으로 인한 상 악 우측 측절치 발치 후 임시 수복물 제작을 주소로 내 원하였다(Fig. 1). 의과적 병력은 없었다. 환자는 상악 전 치부에 고정성 보철물 진료는 원하지 않았고 추후 임플 란트 진료를 위하여 임시 보철물을 제작하기로 결정하 였다.

Copyright@ 2016 The Korean Academy of Stomatognathic Function and Occlusion. (c) This is an Open-Access article distributed under the terms of the Creative Commons Attribution Non-Commercial License (http://creativecommons.org/ licenses/by-nc/4.0) which permits unrestricted non-commercial use, distribution, and reproduction in any medium, provided the original work is properly cited. 
상악과 하악에 알지네이트로 인상채득을 시행하여 진단모형을 제작하였다. 상악 우측 측절치의 근원심 길 이를 측정하였고 이에 맞추어 레진치(DURACROSS, NISSIN DENTAL PRODUCT, Kyoto, Japan)를 준비 하였다. 레진치는 기계적인 유지력 확보를 위하여 치아 구개측 면에 \#2 round bur로 홈을 형성하였다. 기존의 좌측 전치부와 대칭적으로 배열하여 치은측에 유틸리티

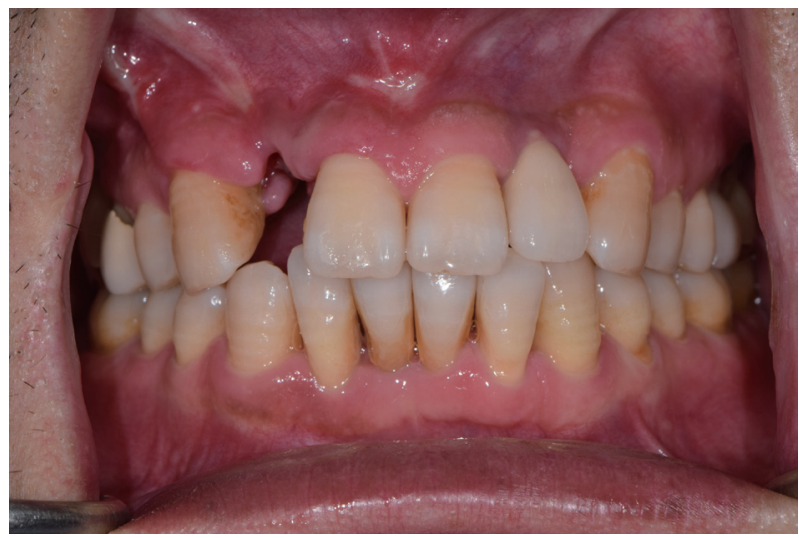

Fig. 1. Initial intraoral photo image.
왁스를 연화하여 모델 상에 고정하였다. 의치상의 유지 력을 위하여 클라스프를 디자인했다. 대합치 모델과의 교합 상태를 확인하여 상악 양쪽 견치와 제1소구치 사 이 공간에 강선이 지나갈 만한 충분한 공간을 확인하였 다. 이 공간을 활용하여 ball 클라스프를 위치시켰다(Fig 2). 위치시킨 레진치와 클라스프를 치과용 석고를 이용 하여 고정하였다(Fig. 3). 이 때 레진치에 치과용 석고가 위치한 부위는 추후 Erkocryl rose와 화학적 결합이 일 어나지 않는 부위가 된다. 따라서 레진치의 순면 전체와 설면의 절단면에 치과용 석고를 위치시켰다. 또한 클라 스프의 순면과 순면에 위치한 언더컷 부위, 그리고 기공 작업에서 필요로 하지 않는 후방 구치부 교합면과 순측 과 구개측 인접면에도 치과용 석고를 바르고 경화시켰 다. 레진치 하방의 유틸리티 왁스를 제거하기 위하여 고 온 압축 증기 분사기를 이용하였다. 모델에 분리제를 적 용하였다. 이 때 분리제가 레진치의 구개면과 하방, 클 라스프에 닿지 않도록 하였다. 가압 공기 분사기를 이용 하여 5 분 간 충분히 건조시켰다.

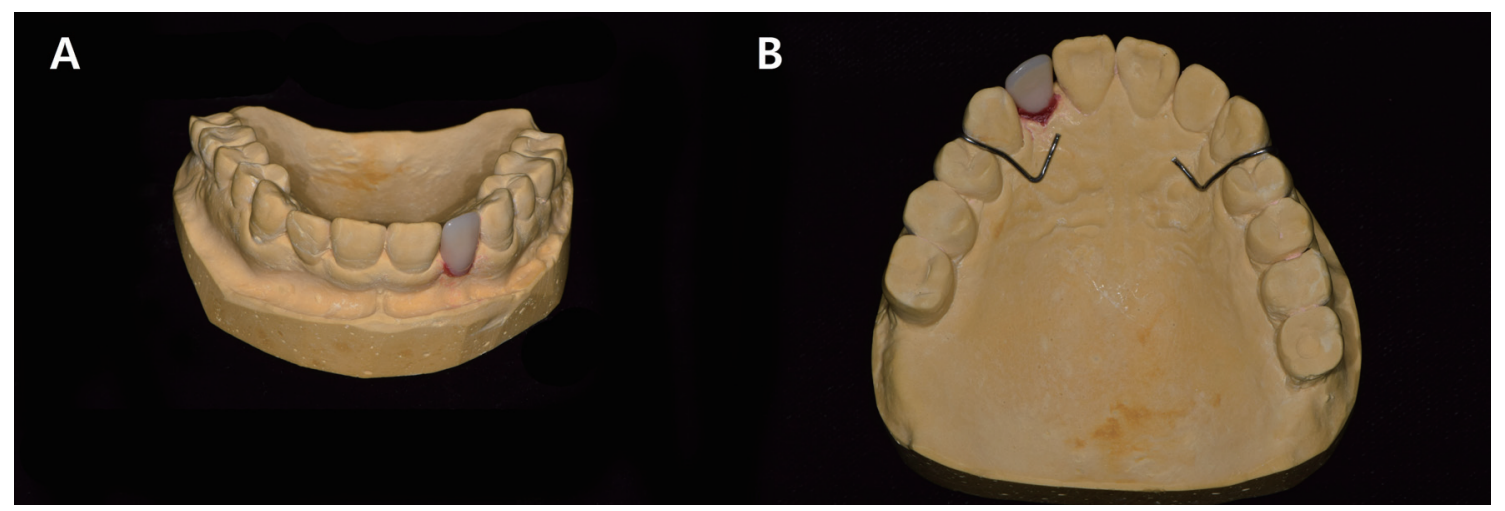

Fig. 2. Working cast. (A) Artificial tooth arrangement, (B) Bended ball clasp.

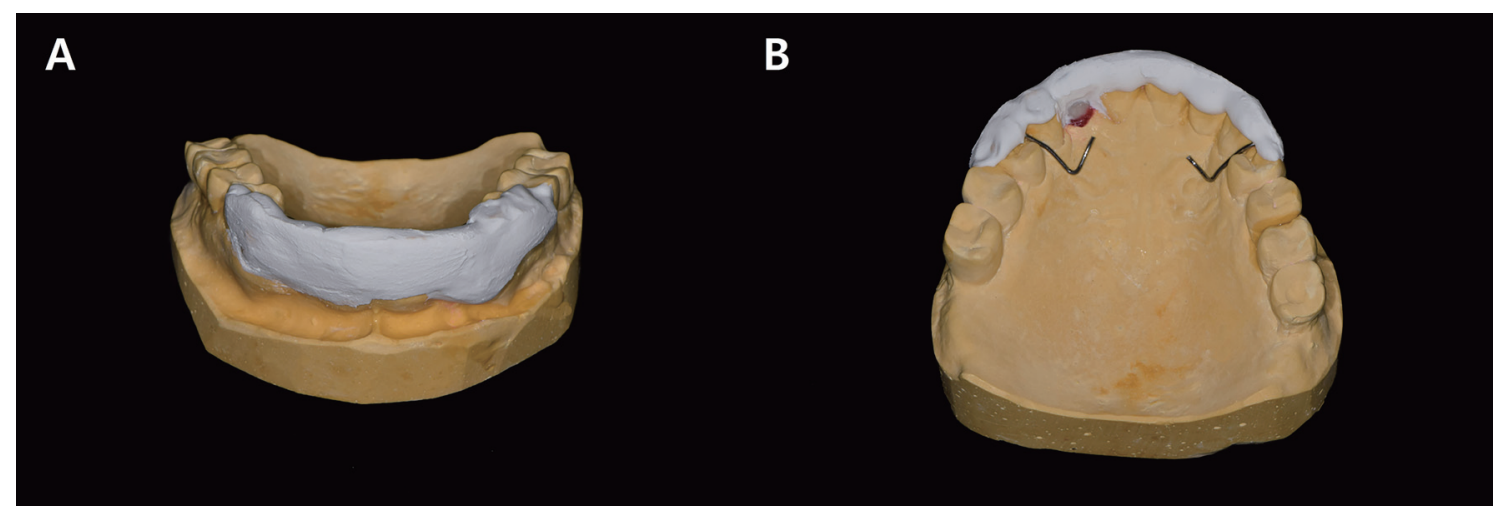

Fig. 3. Block-out by plaster. (A) Frontal view, (B) Occlusal view. 
Biostar (SCHEU-DENTAL, Iserlohn, Germany)를 제조사의 지시에 따라 예열시켜 준비하고 온도를 $190^{\circ} \mathrm{C}$, 160 초로 설정한 후 Erkocryl rose $2.0 \mathrm{~mm}$ 를 위치시켰 다. 가열이 끝나기 1 분 전에 레진치의 구개측 및 구개측 홈 그리고 치아 하방에 분홍색 아크릴릭 레진(ProBase Cold pink, Ivoclar vivadent, Schaan, Liechtenstein)을 적 용하였다. 클라스프 하방에도 아크릴릭 레진을 적용하 였다. 가열 시간을 채운 후 신속하게 Erkocryl rose를 모 델에 적용하고 가압, 냉각을 180 초간 시행하였다. 이 때 압접된 Erkocryl rose는 레진치 하방에 위치한 아크릴릭 레진과 화학적 결합을 이루어 레진치와 의치상 간의 화 학 결합을 이루게된다(Fig. 4). Erkocryl rose 및 아크릴 릭 레진의 경화, 냉각을 마친 후 의치의 디자인에 맞게 필요한 부분만을 남기고 제거하였다. 계획된 디자인대 로 마무리 과정을 시행하였다. 열형성을 이용한 재료로
외형이 형성되어 추가적인 연마 과정은 거의 필요로 하 지 않았다.

환자의 구강 내에 임시 의치를 시적하였다(Fig. 5). 임 시 의치의 적합도를 확인하였고 유지력, 교합을 정검하 였다. 환자에게 임시 의치를 시적하여 유지, 안정, 심미 적으로 만족할만한 임상 결과를 보였다.

두 번째 증례의 환자는 27 세의 여자 환자로 문에 부딪 혀서 상악 우측 중절치와 측절치의 상실을 주소로 내원 하였다. 치과적, 의과적 병력에 특이사항은 없었다. 전반 적으로 양호한 치관 치근 비율을 보이며 치주적으로 문 제가 없었다. 환자는 결혼을 2주 가량 앞둔 상황이었고 심미적이면서 빠른 전치부 수복이 필요한 상황이었다. 상악 전치부에 고정성 보철 진료는 원하지 않았고 추후 임플란트 진료를 위하여 임시 보철물을 제작하기로 결 정하였다.

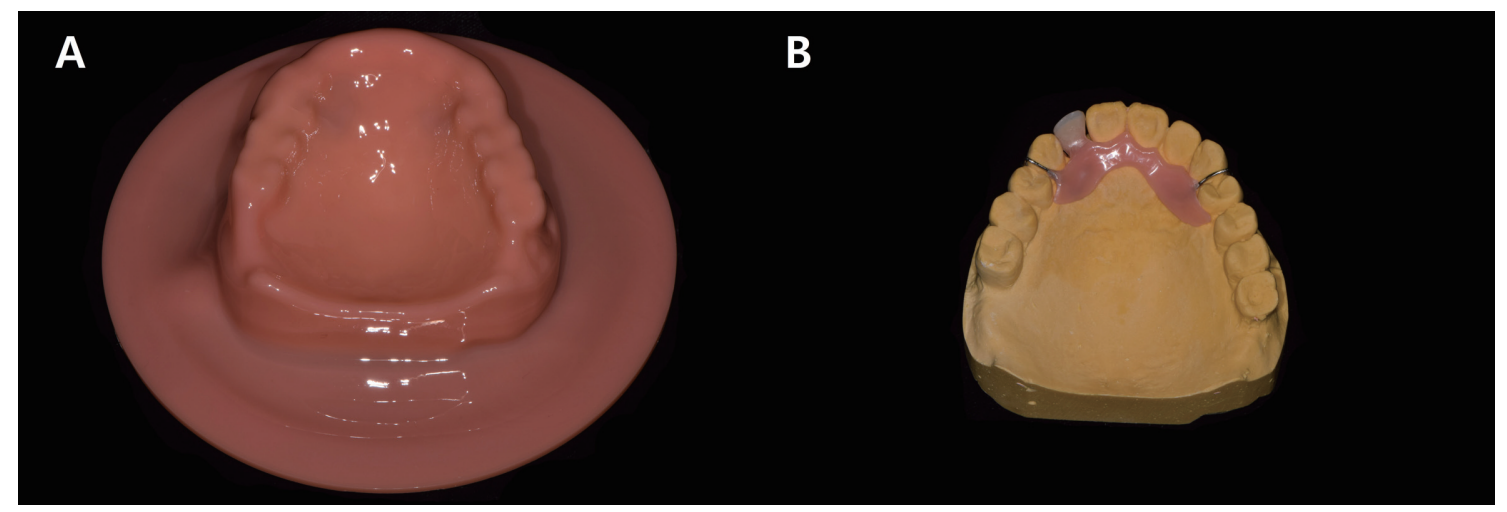

Fig. 4. Thermoforming material. (A) Pressed Erkocryl rose plate, (B) Fabricated interim denture.

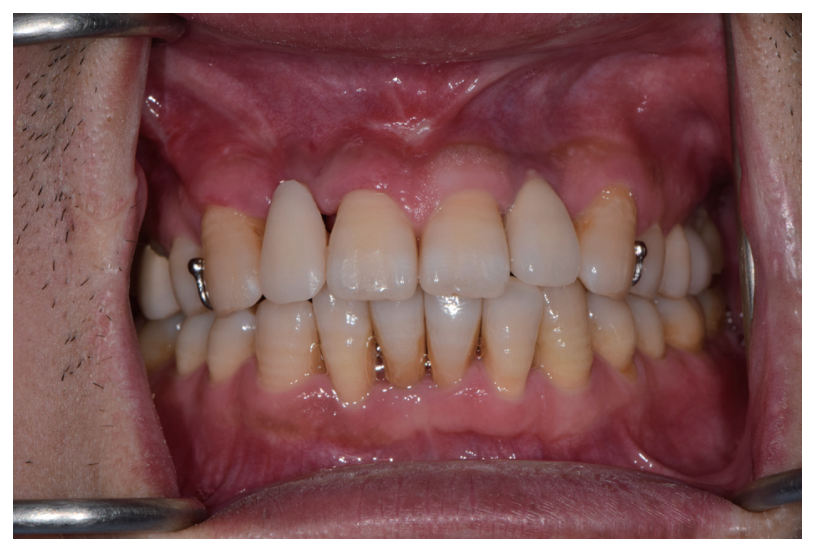

Fig. 5. Interim denture setting. 
상악 좌측 중절치와 측절치의 길이를 측정하였고 이 에 맞추어 레진치(DURACROSS, NISSIN DENTAL PRODUCT)를 준비하였다. 레진치는 기계적인 유지력 확보를 위하여 치아 구개측 면에 \#2 round bur로 홈을 형성하였다(Fig. 6). 이 후 클라스프의 디자인과 레진치 의 고정, 의치상 제작 과정은 첫 번째 증례와 같은 방식 으로 진행하여 임시 의치를 완성하였다(Fig. 7).

환자의 구강 내에 임시 의치를 시적하였다. 결혼을 앞 둔 환자의 개인적인 상황을 고려하여 심미와 발음을 중 점적으로 정검하였다. 환자는 레진치의 색조와 자연치 에 대한 대칭에 만족하였고, “식사하셨어요? 선생님”과 같은 발음을 시행시켜 혀가 구개에 접촉하며 내는 발음 에 대한 평가하여 양호한 발음 상태를 확인하였다. 그밖 에 임시 의치의 적합도를 확인하였고 유지력, 교합을 정 검하였다. 환자에게 임시 의치를 시적하여 유지, 안정, 심미적으로 만족할만한 임상 결과를 보였다(Fig. 8).

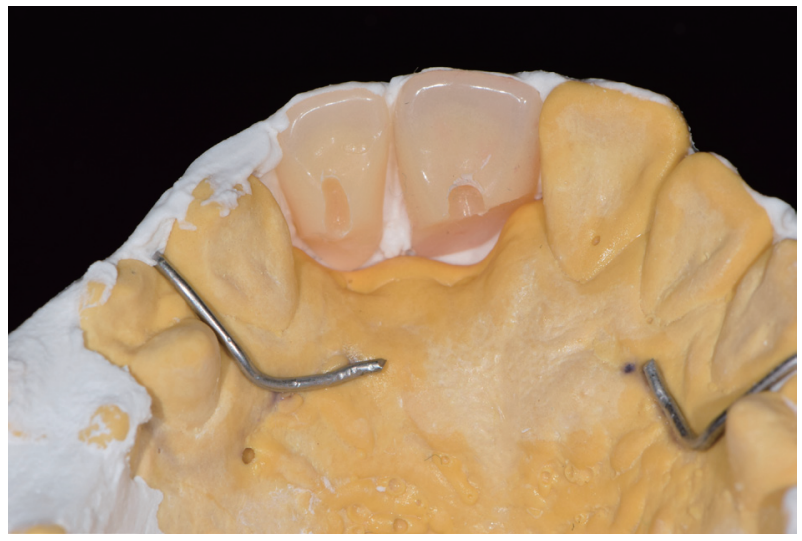

Fig. 6. Washed-out utility wax which fix the artificial teeth.

\section{고찰}

즉시의치는 '자연치의 발거 후 즉시 사용이 가능하도 록 제작된 총의치 또는 가철성 국소의치' 라고 정의된 다. ${ }^{3}$ 이렇게 만들어진 의치는 일반적인 의치보다 치과의 사나 환자 모두에게 도전적인 술식이다. 왜냐하면 사전 에 의치를 시적할 수 없기 때문에, 환자들은 의치를 장 착하는 날 맞지 않거나 결과적으로 나타나는 외모에 완 전히 만족하지 않을 수 있다. 치과의사는 이렇게 발치 후 바로 사용하는 임시 의치의 한계성에 관하여 치료가 시작되기 전 충분히 설명해야 하고, 환자들은 이것을 완 전히 이해해야 한다. ${ }^{6}$ 전치부에 급작스럽게 일어난 치 아 상실은 임시 수복물을 통하여 심미와 발음의 저하를 회복하는 것이 필요하다. ${ }^{3,4}$ 본 증례는 열형성을 이용하 여 전치부 임시 의치를 제작하였다. 이 과정은 열형성을 위한 가열과정과 plate를 모델에 가압하는 과정만을 거

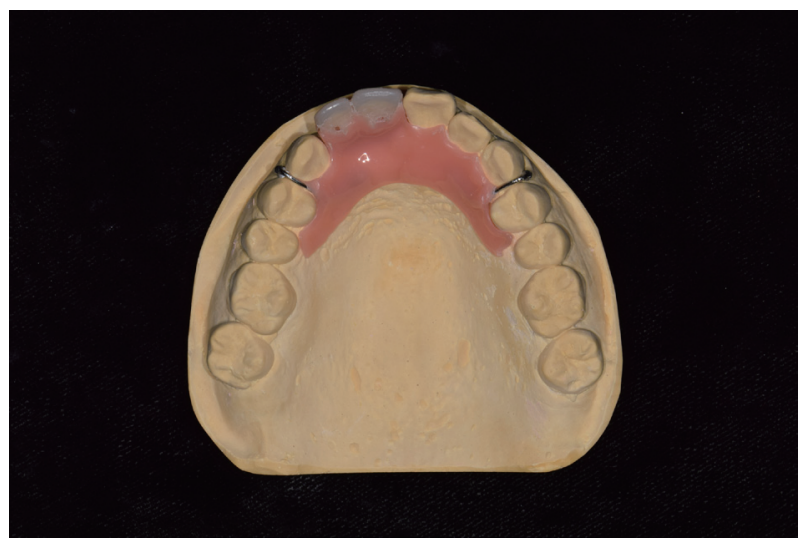

Fig. 7. Fabricated interim denture.

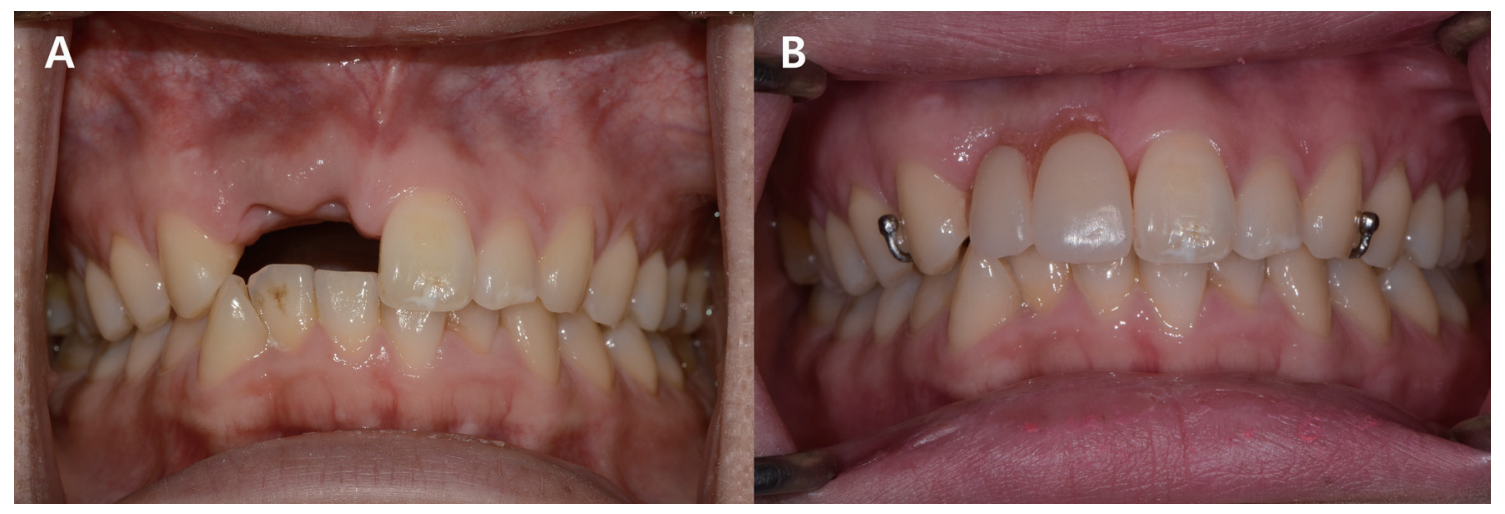

Fig. 8. Clinical view. (A) Initial intraoral photo image, (B) Interim denture setting. 
친다. 이러한 절차는 의치상 형성을 위한 플라스킹 과정 혹은 자가중합 아크릴 레진 중합 과정을 간단하게 함으 로써 빠르게 임시 의치를 만들어 낼 수 있다. 또한 이렇 게 형성된 의치상의 두께는 미리 제작된 plate를 열연화 하여 펼쳐낸 것이기 때문에 거의 균일한 두께의 의치상 을 얻을 수 있다. 미리 제작된 plate의 두께를 선택함으 로써 균일하면서도 원하는 두께의 의치상을 수월하게 얻어낼 수 있다. 특히 이미 표면이 처리된 plate를 이용 하여 열형성을 이루어내기 때문에 의치상의 질감이 우 수하여 별도의 연마 과정이 거의 필요하지 않다. 이렇게 얻어낸 의치상은 빠른 수복으로 인한 환자 만족도는 물 론이거니와 균일하면서도 적절한 두께로 인하여 발음에 지장을 주지 않을 수 있다. 또한 우수한 연마 상태는 환 자로 하여금 이물감을 적게 느끼고 처음 사용하는 의치 에 편안함을 느끼게 할 수 있다. 사용한 재료에 대해 살 펴보자면, PMMA 계열의 plate를 사용하여 만들어진 의 치상이기 때문에, 기존의 의치상 첨상 및 수리에 사용해 오던 재료들과 호환이 가능하다. 따라서 발치 후 변화하 는 구강 내 상황에 유동적으로 대처가 가능하다.

본 증례에서 사용한 재료는 plate를 이용하여 의치상 을 만들어 내기 때문에 적은 부위의 결손 부위를 수복하 기 위해서도 하나의 plate를 소모해야 한다는 단점이 있 다. 물론 수복하고자 하는 부위만 모델을 트리밍하여 여 러 개의 모델을 한 plate로 열형성하는 것이 가능하지만, 빠른 수복을 위하여 환자의 내원 즉시 치과 기공작업이 시작된다는 관점에서 볼 때, 다른 환자와 함께 기공작업 과정을 진행할 가능성은 매우 낮다. 따라서 최종 보철물 에 비하여 사용되는 기본 재료의 소모가 크다는 단점을 지닌다. 또한 압력을 통한 모델과의 압접을 이용하기 때 문에 언더컷 하방으로 적절하게 추가적인 자가중합 아 크릴 레진의 적용이 필요하다. 이 때 과도한 양의 아크 릴 레진을 적용하게 되면 적용한 레진이 내면에 퍼진 상 태로 의치상이 완성되는데, 이는 이미 제작된 plate를 사 용함으로써 얻을 수 있는 우수한 질감의 내면이라는 장 점을 상쇄하게 된다. 그리고 레진치와의 화학적 결합을 이루기 때문에 plate와의 압접 후 화학적 결합을 이루는 과정에 대한 세밀한 처리과정이 필요하다. 왜냐하면 화 학적으로 결합이 이루어져야 할 부위와 그렇지 않은 부 위에 대한 처리가 분명하게 구분되어야 하기 때문이다. 예를 들자면 치아의 순면과 절단연은 의치상과의 화학 적 결합이 필요로 하지 않다. 따라서 이러한 부위에는 플라스터를 이용한 블록 아웃이 필요로 하게 되는데 이
는 치과 기공작업을 하는 사람의 숙련도에 따라 매우 간 단하게 의치를 제작할 수 있게도 할 수 있지만, 잘못 형 성하여 준 경우 기공작업 과정을 처음부터 다시 해야 할 수 있을 만큼의 치명적인 문제를 발생시킬 수 있다. 특 히 재작업의 경우 기존의 모델을 재사용할 수 없는 경우 로 이어지는 경우가 많기 때문에 각별한 주의가 필요로 한다.

본 증례에서는 전치부 치아 상실로 인하여 수복이 필 요로 하는 환자에게 임시 수복물을 이용하여 신속한 수 복을 이루었다. 환자는 발음과, 심미적으로 만족할 만한 결과를 얻었고 최종 보철물을 사용하기까지 임시 수복 물을 사용하기에 만족할만한 결과를 얻었다.

\section{결론}

임시 의치 제작을 위하여 사용되는 방법은 전통적으 로 열중합 레진 혹은 자가중합 레진을 사용하는 방법이 사용되어왔다. 그러나 본 증례는 PMMA 재료를 이용하 여 열형성 기술을 사용하여 임시 의치를 제작하였다. 제 작 과정은 간단하면서도 신속하게 이루어졌으며, 환자 에게 적용한 결과 기능적과 심미적으로 모두 만족할만 한 결과를 얻을 수 있었다.

\section{References}

1. Lee JH. Fabricating an immediate denture for a medically compromised elderly patient. J Prosthet Dent 2015;113:277-81.

2. Swoope CC, Depew TE, Wisman LJ, Wands DH. Interim dentures. J Prosthet Dent 1974;32:604-12.

3. No authors listed. The glossary of prosthodontic terms. J Prosthet Dent 2005;94:10-92.

4. Woloch MM. Nontraumatic immediate complete denture placement: a clinical report. J Prosthet Dent 1998;80:391-3.

5. Truckenmüller R, Giselbrecht S, Rivron N, Gottwald E, Saile V, van den Berg A, Wessling M, van Blitterswijk C. Thermoforming of film-based biomedical microdevices. Adv Mater 2011;23:131129.

6. Smith DE. Interim dentures and treatment dentures. Dent Clin North Am 1984;28:253-71. 


\section{열형성 기술을 활용한 임시 의치 수복 증례}

\section{윤준구, 송영균*}

단국대학교 치과대학 치과보철학교실

사고로 인하여 갑자기 치아를 상실하게 된 환자에게 정신적 안정, 심미성과 기능을 회복하기 위하여 빠른 임시 보철물 수복이 필요하다. 본 증례는 외상으로 인하여 예상치 못한 치아 상실이 발생한 환자에게 열형성 기술(thermoforming technique)을 이용한 수복을 시행하여 만족할 만한 결과를 얻었기에 보고하는 바이다.

(구강회복응용과학지 2016;32(2):135-40)

주요어: 열형성; 치아 상실; 임시 의치 